\title{
12 Truthmaking, Satisfaction and the Force-Content Distinction
}

\author{
Friederike Moltmann
}

\subsection{Introduction}

Standard views in philosophy and formal semantics center around the notion of a proposition, an entity needed, or so it appears, to fulfill several functions at once: being the meaning of (declarative) sentences (and that-clauses in particular), being the (primary) bearer of truth, being the shareable object (or content) of propositional attitudes and of illocutionary acts. The availability of apparent propositional anaphora and quantifiers such as that, something, and everything as well as free relatives like what Mary claims in place of that-clauses seems to confirm the status of that-clauses as referential terms and thus the objectual status of propositions. Propositions are standardly seen as separate from force: different illocutionary act types (with different forces) can have the same propositional content, as can different propositional attitudes (with different attitudinal modes). In order to avoid the too coarse-grained notion of content associated with the conception of propositions as sets of possible worlds, it has become common in philosophy of language, to adopt a structured conception of propositions. The structured-propositions view leads to the notorious problem of the unity of the proposition, however. This is the problem how, for example, the structured proposition <the property of being happy, John> can be true or false and have the particular truth conditions it is meant to have, namely to be true just in case John is happy, rather than, say, John being distinct from happiness. A solution to the problem that has been pursued recently consists in giving up the force-content distinction and taking illocutionary acts to be acts of predication applying to the propositional constituents, thus providing the unity and the truth-evaluability of the proposition (Hanks 2015).

In this chapter, I outline a very different view, which does away with the notion of a proposition as an entity and avoids the problem of the unity of the proposition while subscribing to a fine-grained notion of content. On that view, propositions do not play a role as entities fulfilling the various functions at once. That-clauses do not act as proposition-referring terms, and pronouns and quantifiers like that and

DOI: $10.4324 / 9781003105152-16$ 


\section{Friederike Moltmann}

something and free relatives like what John believes do not stand for propositions. The starting point instead are the kinds of objects that correspond to illocutionary acts and propositional attitudes, namely what we refer to as claims, beliefs, judgments, requests, promises, intentions, desires, hopes, and decisions. These are what I call "attitudinal objects". ${ }^{1}$ Attitudinal objects divide into illocutionary objects (claims, requests, promises, etc.) and mental objects (beliefs, judgments, intentions, decisions, hopes, etc.). Closely related to attitudinal objects are modal objects, which include obligations, permissions, abilities, options, possibilities, strategies, and laws. Attitudinal objects are extremely well-reflected in natural language, but they are of course not dependent on language. Attitudinal objects are mind- and agent-dependent particulars and are bearers of truth conditions or more generally satisfaction conditions. I take them to be bearers of truthmakers or satisfiers, namely situations or actions that exactly satisfy the attitudinal object, in the sense of Fine's $(2017,2018 \mathrm{a}, \mathrm{b})$ notion of exact truthmaking. Truthmaker semantics, which is based on that notion, allows for a fine-grained notion of content associated with both sentences and attitudinal objects.

Attitudinal objects come with a force (illocutionary objects) or mode (mental objects), though they are not actions. Satisfaction predicates including truth predicates do not apply to acts, but rather to attitudinal objects, and different satisfaction predicates apply to different types of attitudinal objects, reflecting, at least in part, their mode or force. True and false apply to beliefs, assumptions, and claims; comply with, violate, and contravene to requests and commands; fulfill to promises, desires, and hopes, accept and take up to invitations, suggestions, and offers, carry out and realize to intentions and decisions, take and follow to options and strategies. Given the notion of an attitudinal object, force or mode can be cast in terms of conditions on the satisfaction of attitudinal objects, involving actions, situations, and attitudinal objects as satisfiers.

In what follows, I will first recall the standard view of propositions and the force-content distinction, then present challenges to that view from research in linguistics, and finally outline the new view based on attitudinal objects and their satisfaction conditions.

\subsection{The Standard View of Propositions and the Force-Content Distinction}

The standard view, since Frege, is that propositions are entities that act as semantic values of that-clause complements of attitude verbs and provide arguments for the attitudinal relation expressed by such verbs. This gives rise to the relational analysis of attitude reports and illocutionary acts reports as in (1b) for (1a): 
(1) a. John believes that $S$.

b. believe(John, the proposition that S)

That-clauses, on that view, are proposition-referring terms, with propositions being both meanings of sentences and the object or content of propositional attitudes and illocutionary acts.

Pronouns like that and quantifiers like everything and free relatives like what Mary believes, "special" quantifiers or pronouns, as I call them, appear to stand for just the sorts of things that-clauses denote, propositions:

(2) a. Mary believes that.

b. John believes everything Mary believes.

c. John believes what Mary believes.

There are two standard views of what propositions are: sets of worlds and structured complexes consisting (in the simplest case) of a property and an object (structured propositions). The structured-propositions view has become a more widely adopted view among philosophers since it avoids problems with the possible-worlds view such as the identification of logically equivalent propositions. On either view, propositions are taken to be independent of force, providing the semantic values of embedded sentences in various contexts, including as antecedents of conditionals and as disjuncts of sentential disjunctions.

\subsection{Linguistic Challenges of the Standard View}

The standard view appears well-motivated by what the linguistic facts seem to bear on their sleeve; yet the view that embedded clauses stand for force-independent propositions has been challenged by recent and not so recent research in both syntax and semantics.

First, embedded clauses may be associated with different semantic types, associated with different forces. In particular wh-clauses correspond to the semantic types of questions (I asked how tall John is) and exclamations (I am amazed how tall John is), rather than propositions, and those different semantic types are selected by different clause-embedding predicates (Grimshaw 1979). In formal semantics, interrogatives are generally taken to have a different denotations from declaratives and that-clauses (Hamblin 1958, Karttunen 1977). Also imperatives have been taken to have a different denotations from declaratives, e.g. as properties as opposed to propositions (Portner 2007). In addition to different sentence types, mood and modals occurring in the embedded clause may be indicative of force. Depending on the force or mode of the described event, the verb may require a particular mood or the presence of a modal in the embedded clause, and, vice versa, mood or modals may require 


\section{Friederike Moltmann}

particular embedding verbs. Thus, request, which selects directive force, requires a that-clause to be in the subjunctive mood or else to contain a modal like should ("modal concord", Portner 2007):

(4) a. ??? John requested that Bill is at work by 8 .

b. John requested that Bill be at work by $8 /$ that Bill should be at work by 8 .

Thus that-clauses may not stand for force-free propositions, but indicate the type of force selected by the verb.

There have also been various arguments to the effect that that-clauses do not syntactically behave like referential terms, but as predicates of content bearers, which may come with a force (Moltmann 2014, 2017, Moulton 2015). First, there are views according to which that-clauses are in fact relative clauses, given the syntactic behavior of complementizers such as that (Arsenijević 2009, Kayne 2010). As such, that-clauses would modify a silent noun (such as silent fact) or a noun that has subsequently been incorporated into an underlying light verb such as have or make (with believe being derived from have belief and claim from make claim) (Arsenijević 2009, Moltmann 2021). Second, the ability of thatclauses to modify nouns (the belief that $\mathrm{S}$ ) is indicative of a semantic status of clauses as predicates rather than arguments (Moulton 2015).

There is also strong evidence that special quantifiers and pronouns do not actually stand for propositions, but rather for concrete content bearers that incorporate a force or mode. First, quantifiers like something in place of that-clauses take restrictions that could not be predicated of propositions, such as difficult to comply with (John requested something difficult to comply with) (Moltmann 2003a, b, 2013 Chap.4). Second, reports of content sharing involving different attitude verbs are subject to constraints that indicate that what is shared is (kinds of) content bearers that include a force (Moltmann 2003a, b, 2013, Chap. 4). Thus, attitude verbs that involve different forces or modes generally cannot share their content:

(5) a. ??? John hoped what Mary claimed, that it would rain.

b. ??? John imagined what Mary claimed, that it was raining.

c. ??? John decided what Mary predicted, that he would return.

(6) ??? John promised what Mary suspected, that he would return.

Only under special conditions are such sentences acceptable, namely when the described attitudes are coordinated or allow, under focusing, for a lexical decomposition in syntax, into an attitudinal modifier and a more general predicate (John in fact promised what Mary only imagined, John knows what Mary only suspects). The standard view has it that free relative clauses such as what John hopes stand for a force-free content; 
but the fact that reports of sharing such as (5-6) are unacceptable or require special linguistic contexts or efforts on the part of the interlocutors means that that view is mistaken. The unacceptability of $(5 \mathrm{a}$, b) and (6) matches the unacceptability of corresponding sentences with nominalizations:

(7) a. ??? John's hope is Mary's claim.

b. ??? John's imagination is Bill's claim.

c. ??? John's decision is Mary's prediction.

d. ??? John's promise is Bill's suspicion.

Standard views have it that nouns like claim and decision are polysemous standing either for a proposition or an act. The unacceptability of examples like $(7 \mathrm{a}-\mathrm{d})$ again shows that that view is mistaken since those examples should be fine on the proposition-reading.

Observations such as these indicate that propositions do generally not figure as entities in the semantics of sentences. Instead what plays a role is just the sorts of entities we refer to as "John's claim that S", an attitudinal object, or "the claim that S", a kind of attitudinal object sharable by different agents. Attitudinal objects are concrete mental or illocutionary objects that depend on a particular agent; yet they generally come with satisfaction conditions. They form kinds on the basis of being the same in content (provided they share their force or mode), and thus kinds of attitudinal objects are suitable for the role of sharable contents (Moltmann 2013 Chap. 4, 2017, 2019). Some attitudinal objects are (non-material) products of acts, in roughly the sense of Twardowksi's (1911) distinction between actions and products. ${ }^{2}$ Thus assertions are products of acts of asserting, thoughts, products of acts of thinking, requests products of acts of requesting, and questions products of acts of asking. Attitudinal objects are closely related to modal objects, entities like obligations, permissions, possibilities, which likewise have satisfaction conditions. Modal objects may generally endure past the act that may have set them up, attitudinal objects may do so only if they have a modal component. That is, a demand may involve an obligation, an assertion a commitment to truth.

Without this being a place for a detailed linguistic discussion, the linguistic generalizations above give support for a rather different semantics of attitude reports than the standard relational one. Such an analysis will start out with attitudinal objects and that-clauses acting semantically as their predicates, so that a simple attitude report such as (8a) will be interpreted as in $(8 \mathrm{~b})$ :

(8) a. John claims that $\mathrm{S}$.

b. make(John, the claim that $S$ ) 
The semantic analysis of $(8 \mathrm{a})$ as $(8 \mathrm{~b})$ is plausible given recent syntactic views on which $(8 \mathrm{a})$ has an underlying structure as indicated in (9), involving the light verb make and movement of the noun claim from a position (the specifier position of a force projection FP) inside the thatclause to the direct object position of the verb and subsequent incorporation into the verb (Arsenijević 2009, Moltmann 2021a):

(9) a. John claim ${ }_{\mathrm{i}}-$ make $_{\mathrm{i}}\left[{ }_{\mathrm{CP}}\right.$ that $\left.\left[{ }_{\mathrm{FP}} \mathrm{e}_{\mathrm{i}}\left[{ }_{\mathrm{F}}, \mathrm{V}\left[{ }_{\mathrm{IP}} \mathrm{S}\right]\right]\right]\right]$.

The force-projection F', based on a force feature v, will denote a property of attitudinal or modal objects, which will semantically compose with the denotation of claim in its original position in the specifier position of the force phrase, yielding the same denotation as that of claim that $\mathrm{S}$.

That-clauses act as predicates of attitudinal (and modal) objects by giving, at least, their satisfaction conditions. The satisfaction conditions of attitudinal objects are best cast in terms of truthmaker semantics as recently developed by Fine (2017, 2018a,b), rather than possible-worlds semantics. There are three reasons for that. (1) Sets of worlds as contents of attitudinal objects give a too coarse-grained notion of content. (2) Sets of worlds would not be able to distinguish attitudinal (and modal) objects with the modal force of necessity and the modal force of possibility (Moltmann 2020). (3) Truthmaker semantics allows casting certain conditions of force as conditions on actions and attitudinal objects as satisfiers of (other) attitudinal objects (Section 12.5). Truthmaker semantics has a range of motivations mainly from the sort of intensionality arising in non-attitudinal contexts such as conditionals and deontic modals. The possibility of casting force in terms of conditions on truthmakers/satisfiers and falsifiers/violators (Section 12.5) gives new motivations for it.

\subsection{Attitudinal Objects as Bearers of Truth and Satisfaction Conditions}

Attitudinal objects come with satisfaction conditions, which divide into truth conditions and fulfilment conditions. Attitudinal objects such as claims and assumptions have truth conditions; attitudinal objects such as requests and promises have fulfillment conditions. I take satisfaction conditions not to consist in conditions under which an attitudinal object is true or satisfied in a world, but in conditions under which possible or actual (or even impossible) situations or actions verify or satisfy the attitudinal object, in the sense of exact truthmaking or satisfaction of Fine's $(2017 b, 2018 \mathrm{a}, \mathrm{b})$ truthmaker semantics. That is, situations or actions verify or satisfy an attitudinal object such as a claim, assumption, request, promise, intention or decision just in case they are wholly 
relevant for the satisfaction of the claim, assumption, request, promise, intention or decision.

Truthmaker semantics posits as the meaning of declarative and imperative sentences not just a set of truthmakers (satisfiers), but also a set of falsifiers (violators) (Fine 2017, 2018a,b). In Fine's truthmaker semantics, the notions of exact truthmaking or satisfaction and of falsemaking or violation play a central role, though applied to declarative and imperative sentences. The very same notion, however, carries over to attitudinal (and modal) objects. A rudimentary truthmaker view of mental states and mental and illocutionary acts can in fact already be found in Searle (1983), who takes intentions, decisions and requests to be satisfied by actions and assertions and beliefs to be satisfied by states of affairs. One important feature of truthmaker semantics is that it is ontologically neutral: any entity can in principle play the truthmaker role, as long as it serves the overall purposes imposed by the semantics. Situations, actions, as well as attitudinal objects (as answers) play a role as truthmakers or satisfiers of attitudinal objects, and attitudinal objects may require particular types of satisfiers or impose particular conditions on it (Section 12.5). This is a major difference of the present approach to possible-worlds semantics.

Truthmaker semantics is an alternative to the unstructured conception of propositions based on possible worlds. It gives a more fine-grained notion of content, providing a notion of partial content and a notion of subject matter. ${ }^{3}$

Truthmaker semantics when applied to attitudinal and modal objects differs in one important respect from sentence-based truthmaker semantics: not all attitudinal and modal objects have falsifiers/violators. Claims and assumptions do have as falsifiers, namely situations in virtue of which they are false (situations completely relevant for the falsity of the claim). In a more obvious way, requests have violators, actions that violate or ignore the request. However, attitudinal objects with the modal force of possibility do not have falsifiers/violators: a proposal, invitation, offer, or permission cannot be violated.

A sentence $S$ as a predicate of attitudinal or modal objects can be assigned a single meaning that takes that into account, namely the property that holds of an object $d$ just in case $d$ has the same satisfiers as S, and, if $d$ has violators, $d$ shares the same violators as S (Moltmann 2021a):

(11) Truthmaker-based meaning of sentences as predicates of attitudinal or modal objects

For an (imperative or declarative) sentence or clause $S$, $[($ that $) \mathrm{S}]=\lambda \mathrm{d}[\operatorname{pos}(\mathrm{d})=\operatorname{pos}(\mathrm{S}) \&(\operatorname{neg}(\mathrm{d}) \neq \varnothing \rightarrow \operatorname{neg}(\mathrm{d})=\operatorname{neg}(\mathrm{S}))]$.

Here $\operatorname{pos}(d)$ is the set of satisfiers and neg(d) the set of violators of an attitudinal or modal object d. (11) does not yet take into account the 
semantic difference between declaratives and imperatives, which I will come to shortly.

The very same sentence meaning in (11) is applicable to modal objects of different flavors and forces, giving rise to a novel semantics of modal sentences based on an ontology of modal objects (Moltmann 2017, $2020 \mathrm{~b})$. The difference between having and not having violators is also reflected in the applicability of satisfaction predicates. Attitudinal and modal objects can be "fulfilled" or "complied with" only if their modal force is that of necessity rather than possibility. Proposals, permissions, offers, and invitations cannot be "fulfilled", but only "taken up" and an invitation may be "accepted". In addition, predicates of violation are inapplicable to objects like invitations, permissions, offers, and proposals. Obligations can be violated or contravened, and rules or laws can be broken. Offers and invitations can be declined or refused, but that does not amount to a violation but only a refusal of acceptance (satisfaction). The predicate ignore conveys violation with requests and obligations; but with invitations, offers, and permissions it conveys simply failure of satisfaction. What we refer to as "options", "strategies", and "possibilities" are teleological modal objects of possibility. They can be "taken" or "pursued", but not "violated". A strategy may fail, of course, but here failure is a property of the attitudinal object, not its satisfier. An option may be rejected, but that means not taking it, rather than violating it.

Also actions of satisfying permissions, offers, and invitations are evaluated differently from the satisfiers of requests and obligations. Whereas actions can be called "correct" when they satisfy a request or an obligation, actions of taking up a permission, offer, or invitation could only be considered "legitimate", rather than "correct".

\subsection{The Unity of the Proposition Problem}

The attitudinal objects theory displays some similarities with recent actbased conceptions of propositions, in particular, the view endorsed by Hanks $(2015,2018)$ on which propositions are conceived as types of acts of predication, predication in the assertoric, directive, or interrogative way (Hanks 2015, 2018). The present approach shares with that approach, the use of types or kinds of cognitive particulars for the role of propositions as truthbearers and shareable content bearers. ${ }^{4}$ Moreover, it makes use of entities that come with a force, displaying truth conditions, fulfilment conditions or answerhood conditions. However, the motivations are otherwise quite different. First of all, attitudinal objects are not acts. Acts do not have truth or satisfaction conditions (Twardowski 1912, Ulrich 1976, Moltmann 2013 Chap. 4, 2017, 2019, Davis 2021). By contrast, entities like claims, requests, and questions, the products of acts, do, as do entities like rules, beliefs and intentions, which are not generally the products of acts. ${ }^{5}$ Second, it is not just attitudinal objects 
that have satisfaction conditions, but also modal objects. Modal objects include rules and weak permissions and obligations, which are not generally created by acts of predication (a rule may come about by habit rather than fiat; weak permissions and obligations need not result from an act of giving or imposing them).

Hank's view rests on the assumption that propositions, in the sense of structured propositions, are what sentences stand for. If propositions are taken to be structured propositions (say sequences of an (n-1) place property and $\mathrm{n}$ individuals), this raises the problem of the unity of the proposition: how can such a sequence be true or false and have the particular truth conditions it is meant to have? On Hank's proposal, assertoric, directive, and interrogative forces are construed as properties of predicative acts, acts that provide the unity of the propositions and its truth, fulfilment, or answerhood conditions.

The present approach is radically different: sentences come with a truthmaker-based content (i.e. (11)) which, when predicated of an attitudinal or modal object, gives its truth or satisfaction conditions, that is, the conditions under which a possible situation or action satisfies the attitudinal or modal object. The semantics does not have to deal with the issue of how attitudinal objects get their truth or satisfaction conditions: they are mind-dependent objects. It is a matter of the philosophy of mind to account for the intentionality of the mental, not of semantics. The source of the problem of the unity of the propositions resides in the view that propositions are entities that are both the meanings of sentences and truth bearers, a view that is problematic both philosophically and linguistically.

The structured-propositions view has also been motivated by the need to have a more fine-grained notion of content than the possible-worlds-based one. On the present, truthmaker-based approach, content is fine-grained and a structured notion of content is not needed.

\subsection{Forces as Conditions on the Satisfaction of Attitudinal Objects}

Attitudinal objects do not come with a force-content distinction: attitudinal objects comprise both those that come with truth conditions (beliefs, claims) and those that come with fulfilment conditions of various sorts (reflected in the applicability of different predicates of satisfaction). Since propositions do not play a semantic role as objects, attitudinal objects should not be taken to be composed of a proposition and a force. Force can instead be accounted for in terms of conditions on the satisfiers of attitudinal objects as well as on the attitudinal object itself. In what follows, I first propose conditions of force distinguishing traditional categories of speech acts: constatives (assertives), directives, questions, now considered illocutionary objects. Then I briefly turn to other distinctions 


\section{Friederike Moltmann}

among attitudinal objects that are reflected in the applicability of different predicates of satisfaction. I will leave it for another occasion to address the question of what distinctions are reflected otherwise in the semantics of sentences in natural languages, such as the choice of mood and different clause types. ${ }^{6}$

To an extent, conditions on force involve conditions on the sorts of things that can be satisfiers of the attitudinal objects. ${ }^{7}$ There are different views as to what the aim (and thus satisfaction) of an assertion consists in. On the Gricean view, it consists in the addressee having a belief (and constatives thus being directives). On Searle's (1969) view, the illocutionary point of an assertion that $S$ is the speaker's commitment to the truth of $S$. The latter certainly matches the notion of an assertion as an attitudinal object better: assertions have truth conditions, with their truthmakers/falsifiers being situations. Questions have answerhood conditions rather than truth conditions. This means their satisfiers are attitudinal objects that are constatives. Directives are generally taken to have as their satisfiers actions on the part of the addressee. ${ }^{8}$ However, this does not generally hold. Imperatives such as Have a nice day! or Get well soon! have satisfiers that are states or events involving the addressee. This is unproblematic on the present approach: an attitudinal object can have both actions and states or events as satisfiers.

The distinction among different forces or modes does not just consist in differences in the types of possible satisfiers. What plays a central role in the distinction between having truth conditions as opposed to fulfilment or answerhood conditions is the notion of the directions of fit, a notion that originally had been applied to mental states (Anscombe 1957) and later to speech acts as well (Searle 1969, 1983, Humberstone 1992). Truth conditions go with a word/mind-world direction of (i.e. the representation needs to fit the world); fulfillment conditions with a world-word/mind direction of fit (i.e. the world needs to match the representation). The notion of a direction of fit can now be considered a property of attitudinal and modal objects. An assertion, assumption, or belief has a word/mind-world direction of fit (and thus truth conditions). A request, demand, promise, desire, hope, offer, or permission has a "world-word/mind-direction of fit" (and thus fulfilment conditions).

The notion of direction of fit is a normative notion, imposing requirements either on the representation or the world. As such, it shows a striking connection to the applicability of the predicate correct to attitudinal objects or their satisfiers. ${ }^{9}$ The relevant observation is that correct applies to all attitudinal objects with a word/mind-world direction of fit, conveying truth and only truth. ${ }^{10}$ By contrast, it does not apply with a single reading to attitudinal objects with a world-word/ mind direction of fit, though it can apply to the satisfiers of such attitudinal objects, conveying satisfaction. Let us start with correct applying 
to attitudinal objects with attitudinal objects with a word/mind-world direction of fit:

(12) a. John's belief that $S$ is correct.

c. John's claim that $S$ is correct.

b. Bill's guess/speculation/impression is correct.

d. Mary's answer/hypothesis/assumption is correct.

In natural language, correct when applied to a belief or assertion conveys just truth, whether or not the belief or assertion is justified or warranted (Moltmann 2021b). Correct in fact applies with the same reading to guesses, speculations, and impressions, which by nature do not require justification or warrant. Correct furthermore applies to answers, hypotheses, and assumptions just in case they convey a truth, whether or not they are "good" answers, hypotheses, or assumptions. Correct when applied to attitudinal objects with a world-word/mind direction of fit thus does not concern itself with other norms than truth; these are reserved for the application of evaluatives like good. ${ }^{11}$

It is plausible that correct has a single normative meaning: correct holds of an object $o$ just in case $o$ fulfills the norm (or standard of correctness) that is associated with $o$ or that is relevant in the context. The way correctness is understood when applied to beliefs, assertions, guesses, hypotheses, answers and assumptions means that truth is treated as the one intrinsic norm associated with attitudinal objects with a worldword/mind direction of fit. Other types of objects that correct applies to are associated with other norms, e.g. grammaticality for sentences and laws or moral values for punishments.

Correct sharply distinguishes between actions and attitudinal objects that may be their products. A punishment may be correct, but the act of punishing may have been performed incorrectly. Similarly, an assertion or assumption being correct does not entail the act of asserting or assuming being correct (or the making of an assertion or assumption being correct). The latter may be correct because they follow an instruction or order (the relevant contextually given norm), not because they capture or maintain a truth. ${ }^{12}$

Truth as a norm is not an action-guiding norm, but rather is better understood as a teleological norm, that is, a purpose or function, constitutive of a representational object, as Jarvis (2012) has argued. Correctness in that sense applies to artifacts in just the way it applies to mental states, as Jarvis made clear), which in the present context means it applies to non-material products of acts (assertions, assumptions) just as it applies to beliefs (which are not generally products of acts). ${ }^{13,14}$

The word/mind-world direction of fit as a property of attitudinal objects can now be formulated as follows, where $<$ is the part-relation holding among situations: 


\section{Friederike Moltmann}

(14) Word/mind-world direction of fit for attitudinal objects An attitudinal object $o$ has a word-world direction of fit just in case $o$ is associated with a constitutive norm $\mathrm{n}$ and satisfies $\mathrm{n}$ in a world $w$ iff there is a situation $s, s<w$, that makes $o$ true.

Let us then turn to the second observation: correct does not convey satisfaction when applied to attitudinal objects with a world-word/mind direction of fit, but only when applied to their satisfiers. ${ }^{15}$ A request cannot be "correct" (in the sense of being satisfied), but an action meant to satisfy the request might be. Illocutionary objects with a world-word/ mind direction of fit impose a norm on actions performed in response to them, but they are not themselves subject to a norm that is constitutive of them. They may be subject to other norms of course. For example, a request may be considered correct because it complies with a standard of making a particular type of request; a desire may be correct because it is appropriate to have it. But directives are not subject to a single norm that is constitutive of them. Instead they impose an action-guiding or regulative norm on potential satisfiers. Restricted to illocutionary objects, the world-word direction of fit can thus be cast as follows:

(15) World-word/mind direction of fit for illocutionary objects

An illocutionary object $o$ has a world-word/mind direction of fit just in case any action $a$ performed in response to $o$ satisfies the norm imposed by $o$ in a world $w$ iff $a$ is part of $w$ and satisfies $0 .{ }^{16}$

(15) is not yet fully general. Most importantly, it does not apply to attitudes like desires and hopes, which also come with a world-word/mind direction of fit, but do not always require as satisfiers actions, which could be subject to a performance-guiding norm (I hopelwish that I will win). ${ }^{17}$ Hopes and desires, implying a positive emotive response to their satisfaction (under normal circumstances), impose a requirement or norm on the future course of the world, with the emotive response constituting a kind of purpose to be attained by a relevant part of the future course of the world. I will have to leave it with these proposals and remarks on the notion of direction of fit; a more in-depth discussion and comparison with other approaches will have to be left to another occasion. ${ }^{18}$

A characterization of the standard notions of constatives (assertives), directives and questions viewed as illocutionary objects can now be given as follows:

(16) a. An illocutionary object is a constative in case it has a world/ mind-word direction of fit and its verifiers and falsifiers are situations. 
b. An illocutionary object is a directive in case it has a worldword/mind direction of fit and its verifiers (falsifiers) are actions or states of the addressee.

c. An illocutionary object is a question in case it has a worldword/mind direction of fit and its verifiers are constatives.

These distinctions could not simply be carried over to the great variety of mental objects with their various modes and satisfaction predicates. Here still other parameters may be at play. Thus, intentions and decisions, which are generally taken to involve a world-word/mind direction of fit, are not "fulfilled" or "complied with", but rather "carried out" or "realized" or, in the case of decisions, perhaps "implemented" or "executed". What may play a role for the selection of such predicates of satisfaction is a much closer, direct causal connection between the attitudinal object and its satisfier than in the case of requests, hopes, and desires.

While attitudinal objects do not come with a force-content distinction, there is a sense in which attitudinal objects of different forces may share their content, namely if they share the same satisfiers. Such a notion of content will be relevant when accounting for when attitudinal objects of different forces bear logical relations to each other (e.g. an assertion that $\mathrm{S}$ is an answer to the question whether $\mathrm{S}$, a decision to do $\mathrm{X}$ produces an intention to do X). Yet that does not mean that attitudinal objects are composed of a content (proposition) and a force.

\subsection{Conclusion}

This chapter has addressed the force-content distinction from the point of view of a novel semantics of attitude reports and independent sentences in which an ontology of attitudinal objects takes center stage. Various linguistic facts indicate that force-free propositions do not actually play the role in the semantics of attitude reports that they are standardly taken to play. Rather attitudinal objects play a central role, though not as semantic values of that-clauses. That-clauses rather act as predicates of attitudinal objects, with conditions on force being imposed by the embedding verb as well as possibly mood and modals occurring in the clause. Likewise independent sentences act as predicates of attitudinal objects, more specifically locutionary objects, with sentence mood restricting the sorts of illocutionary objects of which they may hold.

Making use of truthmaker theory allows for a fine-grained notion of content for attitudinal objects and permits formulating conditions of force in terms of conditions on their satisfaction. Different conditions on force and the corresponding differences among satisfaction predicates reflect the presence or absence of violators, different ontological types of 
possible satisfiers, norms or purposes imposed on attitudinal objects or potential satisfiers, as well as causal connections to satisfiers. Such conditions could hardly be formulated within a possible-worlds conception of content. Rather they support a truthmaker approach, with situations, actions and attitudinal objects being able to act as satisfiers or violators of attitudinal and modal objects.

\section{Acknowledgments}

I would like to thank Jane Grimshaw, Peter Hanks, Benjamin Nelson, Gary Ostertag, Indrek Reiland, Craige Roberts, Michael Schmitz, Paul Portner and two anonymous referees for very helpful comments on an earlier version of this chapter.

\section{Notes}

1. See Moltmann (2003a, b, 2013, Chap. 4, 2014, 2017, 2019).

2. Products here are best understood the sense of abstract artifacts of Thomasson (1999), which for her include laws - modal objects. See Moltmann $(2017,2019)$ for a clarification of the notion of an attitudinal object in relation to Twardowksi's action-product distinction.

3. Given truthmaker semantics, John believes that Mary is happy does not entail John believes that Mary is happy and 2 is prime. Truthmaker semantics as such does not deal with the mode-of-presentation problem, though. But see Moltmann (2021a) for a proposal.

4. This accounts for one difficulty for the standard notion of a proposition as an abstract object, its graspability.

5. A rule may come about by habit; a belief may be an implicit belief, thus not the result of thinking; an intention precedes the corresponding intentional act, rather than being created by it (Searle 1983).

6. There is a debate, which needs to be set aside in the present context, as to what extent forces should be considered the content of sentence mood (McGinn 1977).

7. This may also apply to expressive attitudinal objects if their satisfiers are taken to be situations involving a subjective property.

8. There is much less of a correlation between forces and embedded sentences. As we have seen, that-clauses can give the content of both assertions and requests, depending on mood or the presence of a modal. Embedded interrogatives may give the content of questions (Mary asked who came), inquiries (Mary wondered who won), knowledge (Mary knows who won) and assertions of a sort (Mary announced who won). Infinitives often serve to characterize directive attitudinal objects whose satisfiers are actions, but not generally so (John expects to be healthy). This is a serious difficulty for Hanks (2015), who must assume a strict correlation of sentence types with force.

9. In what follows, it is important to truly pay attention to linguistically reflected intuitions, setting aside philosophical preconceptions about what correctness amounts to.

10. See also Stalnaker (1984: 80) as well as Humberstone (1992: 71). Stalnaker took the applicability of correct conveying truth to be a characteristic of "acceptance attitudes". 
11. Some philosophers impose further epistemic conditions on the correctness of beliefs or assertion (e.g. Williamson 2000). That does not seem to match linguistic intuitions regarding the applicability of correct: it is not possible for an assertion to be true while also being incorrect (because unjustified). Interestingly, true is hardly acceptable with guesses, speculations, impressions, and assumptions, noted independently by Humberstone (1992: 71) and Moltmann (2021b). This indicates that when applied to attitudinal objects, only true that implies warrant, not correct. (This does not hold, of course, for the notions that philosophers may have in mind when using the nouns truth and correctness.)

12. See also (Humberstone 1992: 68), who points out that one can hold a false (incorrect) belief, yet not make a mistake holding it.

13. When normativity is linked just to actions, truth would then be taken to be constitutive of the norm associated with believing, by imposing the condition "if one ought to believe p, then p" (Boghossian 2003; Gibbard 2003). Such conditions on adopting or maintaining a belief are problematic, however (Glüer and Wikforss 2009). Truth is not the aim of believing in the sense in which the fulfilment of moral values is what certain types of actions and decisions should aim for. The norms for actions of adopting or maintaining a belief may simply be a contextually given norm.

14. Not only correct conveys truth (and only truth) with beliefs and assertions, but also other normative predicates, for example right and, for falsehood, wrong, as do corresponding predicates in other European languages. This supports the generalization that predicates of correctness convey truth and just truth when applied to attitudinal objects that have truth conditions.

15. Jarvis (2012) takes correctness to also apply to intentions. However, intentions could only be correctly realized, with correctly applying to the action that aims to realize the intention, not the intention itself.

16. "In recognition of" is meant to capture Searle's (1983) point that only actions by way of satisfying a request or intention can satisfy the request or intention.

17. Note that correct does not apply to their satisfiers of desires, decisions, intentions, and hopes, is seems, because the latter do not impose a social norm to be recognized as such by the interlocutors.

18. See, for example, Humberstone (1992), for a non-normative account of the notion of direction of fit, in terms of controlling intentions that accompany attitudes. Jarvis (2012) associates a constitutive norm both with beliefs and desires.

\section{References}

Anscombe, G.E.M. 1957. Intention. Blackwell.

Arsenijević, B. 2009. "Clausal Complementation as Relativization”, Lingua 119: 39-50.

Boghossian, P. 2003. "The Normativity of Content”, Philosophical Issues 13: 31-45.

Davis, W. 2021. "Propositions as Structured Event Types", Philosophy and Phenomenological Research. 102.3, 665-92.

Fine, K. 2017. "Truthmaker Semantics", in A Companion to the Philosophy of Language, edited by B. Hale, C. Wright and A. Miller. John Wiley \& Sons. 11: 609-33. 
11: $634-64$.

Gibbard, A. 2003. “Thoughts and Norms”, Philosophical Issues 13: 83-98.

Glüer, K. and A. Wikforss. 2009. "Against Content Normativity”, Mind 118: 31-70.

Grimshaw, J. 1979. “Complement Selection and the Lexicon”, Linguistic Inquiry 10: 279-326.

Hamblin, C. 1958. "Questions”, Australasian Journal of Philosophy 36: 159-68. Hanks, P. 2015. Propositional Content. Oxford University Press.

- 2018. "Types of Speech Acts", in New Work on Speech Acts, edited by

D. Fogal, D. Harris and M. Moss. Oxford University Press: 123-43.

Humberstone, I.L. 1992. "Direction of Fit", Mind 1: 59-83.

Jarvis, B.W. 2012. “Norms of Intentionality: Norms That don't Guide”, Philosophical Studies 157: 1-25.

Karttunen, L. 1977. "Syntax and Semantics of Questions", Linguistics and Philosophy 1: 3-44.

Kayne, R. 2010. "Why Isn't This a Complementizer?”, in Comparisons and Contrasts, edited by R. Kayne. Oxford University Press: 190-227.

McGinn, C. (1977): 'Semantics for Nonindicative Sentences', Philosophical Studies 32, 301-311.

Moltmann, F. 2003a. “Nominalizing Quantifiers”, Journal of Philosophical Logic 32: 445-81. 135: 70-118.

2003b. "Propositional Attitudes Without Propositions", Synthese

. 2013. Abstract Objects and the Semantics of Natural Language.

Oxford University Press.

. 2014. "Propositions, Attitudinal Objects, and the Distinction Between

Actions and Products”, Canadian Journal of Philosophy 43 (5-6): 679-701.

-2017. "Cognitive Products and the Semantics of Attitude Reports and

Deontic Modals", in Act-Based Conceptions of Propositions: Contemporary

and Historical Contributions, edited by F. Moltmann and M. Textor. Oxford University Press: 254-90.

. 2019. "Attitudinal Objects. Their Importance for Philosophy and

Natural Language Semantics", in The Act and Object of Judgment, edited by

B. Ball and C. Schuringa. Routledge: 180-201.

- 2020. "Clauses as Semantic Predicates. Difficulties for Possible-

Worlds Semantics", in Making Worlds Accessible: Festschrift for Angelika

Kratzer, edited by R. Bhatt et al. University of Massachusetts at Amherst.

- 2021a. "Truthmaker-Based Content: Syntactic, Semantic, and

Ontological Contexts", Theoretical Linguistics, 47 (1-2), 155-87.

Synthese 198: 689-716.

Moulton, K. 2015. "CPs: Copies and Compositionality", Linguistic Inquiry 46: 305-42.

Portner, P. 2007. "Imperatives and Modals”, Natural Language Semantics 15 (1): 351-83.

Searle, J. 1969. Speech Acts: An Essay in the Philosophy of Language. Cambridge University Press. 1983. Intentionality. Cambridge University Press. 
Stalnaker, R. 1984. Inquiry. MIT Press.

Thomasson, A. 1999. Fiction and Metaphysics. Cambridge University Press.

Twardowski, K. 1911. "Actions and Products. Some Remarks on the Borderline of Psychology, Grammar, and Logic”, In J. Brandl \& J. Wolenski (eds.): Kazimierz Twardowski. On Actions, Products, and Other Topics in the Philosophy, edited by J. Brandl and J.W. Amsterdam and Atlanta: Rodopi, 103-32. 1999.

Ulrich, W. 1976. "An Alleged Ambiguity in the Nominalizations of Illocutionary Verbs”, Philosophica 18 (2): 113-27.

Williamson, T. 2000. Knowledge and Its Limits. Oxford University Press. 